\title{
Preceptors and patients - the power of two: Nursing student experiences on their first acute clinical placement
}

\section{Ainstey James}

School of Nursing \& Midwifery, Monash University Gippsland Campus, School of Nursing, Churchill, VIC, Australia

\section{Ysanne Chapman}

Associate Professor, Monash University, School of Nursing and Midwifery, Gippsland Campus, Churchill, VIC, Australia

\section{ABSTRACT}

Background: There are several reasons postulated for undergraduate nursing students discontinuing their studies; one being the experiences exposed to during clinical placement. This research explores and describes the experiences of second year undergraduate nursing students at one University in Victoria, Australia undertaking their first acute clinical placement. In particular, it offers insight into how these experiences influence their journey as a student and their future career in nursing. Method: A qualitative approach using a Heideggerian lens was applied to this research. Interviews were taped and transcribed verbatim to form a text of each participant's response. Analysis congruent with a hermeneutic interpretive phenomenological process was used to interpret meaning of these experiences. Results: Three main themes emerged: being overwhelmed and confronted; patients as people and perceptions of preceptors. A number of sub-themes were also expressed within the context of the three main themes. The themes allowed for more meaningful understanding of, and deeper insight into, the students' experiences when exposed to the milieu of an acute clinical placement. Conclusions: Findings inform why some students consider discontinuance of their studies and how the experience impacts on decisions about future nursing practice. This research is useful to tertiary institutions in preparing students, placement areas and staff who preceptor students with the aim of facilitating positive experiences and assisting students' motivation in future clinical placements.

KEYWORDS: clinical placement; qualitative research; nursing students; patients; phenomenology; preceptors

\section{INTRODUCTION}

Fxperiences on clinical placement can have - significant influence on career choices made by undergraduate nursing students (Spouse, 2000). Such experiences may have implications for students continuing their nursing studies and the areas of nursing in which they choose, or not choose, to practice. When reviewing the literature it became apparent that there was limited research explaining the meanings of 
experiences of undergraduate nursing students on clinical placement; especially those students undertaking acute clinical placement for the first time.

The aims of this research were to:

- explore and describe the experiences of second year undergraduate nursing students undertaking their first acute clinical placement and how such experiences influenced their journey as students and their future career in nursing, and

- attach meaning to these experiences and identify both positive and negative experiences of clinical placement.

This paper explores and describes the experiences of second year undergraduate nursing students who undertook their first acute clinical placement. The research findings may have implications for the university, the clinical facility and the students participating in the research study. These implications may raise issues concerning why some students discontinue study, or choices students make regarding where they practice as future registered nurses.

\section{BACKGROUND - CLINICAL IS THE PINNACLE ${ }^{1}$}

Australia has a shortage of nursing workforce placing pressure on health care professionals and the health care system in which they currently practice. In 2001 8,500 undergraduates began their degrees, however by 2004, only 5,702 graduate nurses entered the workforce; thus a shortfall had already been created as completion rates were significantly less than commencing numbers (Beadnell, 2006). The Australian Health Workforce Advisory Committee (AHWAC) (2004) report, estimated that to meet demands of nursing workforce, there needed to be at least 10,182 graduate nurses in 2006 (Beadnell, 2006). There are several reasons postulated for significant loses in undergraduate nursing students. One reason proposed here is the impact clinical placement experiences have on students during their undergraduate education.
It is this clinical experience, together with student expectations, beliefs of nursing as a profession and relationships with preceptors that can become pivotal in the undergraduate nurse's journey. The literature suggests that exploration of undergraduate nursing students' experiences of clinical placements has been the topic for nurse researchers for at least a decade (Beadnell, 2006; Cahill, 1996). Some researchers have provided meaning for this phenomenon, where others have implemented strategies to assist in providing a positive clinical experience. Some contemporary findings appear to indicate that undergraduate nursing students worldwide continue to have similar clinical experiences (Beadnell, 2006; Cope, Cuthbertson, \& Stoddart, 2000; Randle, 2001)

\section{Inclusiveness and acceptance}

Cahill (1996) indicated that students place significant emphasis on the attitudes of trained nurses towards them as students. Students identified characteristics such as a consistent approach, a genuine nature, and respect, as qualities of positive role models, with such qualities determining the degree of success experienced on clinical placement. Having time for students, listening to them and valuing their opinions were important qualities in the nurturing of positive relationships between students and their preceptors (Cahill, 1996). Clinical placements not only provide a technical learning environment but also a social context to learning which facilitates being accepted into a nursing culture.

According to Cope et al. (2000) acceptance can be achieved on two levels, socially and professionally; social acceptance may be offered to any student at any time but, professional acceptance may only be offered when clinical competence is displayed. Cope et al. (2000) reported students may feel vulnerable and isolated, heightened by their novice position, and may feel marginalized, powerless and fear rejection. Students on clinical placement need to receive support that incorporates social, emotional and professional aspects. As

${ }^{1}$ Clinical is the Pinnacle was taken directly from an article by Beadnell (2006). 
a result of this support, students may feel more confident if they experience social inclusion, which can often ease the familiarisation process and leave the way open for the demonstration of clinical competence and thus professional acceptance (Cope et al., 2000).

\section{Great expectations}

Preconceived expectations and beliefs of nursing as a profession may have a significant influence on undergraduate students' experience when undertaking clinical placements. Spouse (2000) found strong preconceptions of nursing culture and how students will practice significantly influenced choices made regarding continuation with their course; this appeared to be irrespective of academic performance or setbacks. Some studies suggest that nursing students view nurses as nurturing, angelic, patient, humorous and compassionate, not only towards people in their care but also towards those wanting to become nurses themselves (Macguire, 1996 \& Smith, 1992 cited in Spouse, 2000).

These views coupled with students' beliefs and popular images can at times be in conflict with reality, resulting in dissonance, disillusionment and sublimation (Spouse, 2000). Spouse (2000) suggested dissonance and disillusionment may be linked to conflicts between a professional model of nursing practice as presented by academics, and a bureaucratic mode instilled in clinicians that focuses on functional practices. She also proffered sublimation as the end result of students adopting the practices and beliefs of the clinical culture they were experiencing as a way of survival or hoping for acceptance.

\section{The influence of significant others}

Nursing students interact with many different people during clinical placement; lecturers, patients, doctors, allied health personal and nurses. Randle (2001) identified that registered nurses appeared to have the most influential impact on undergraduate nursing students' self-esteem. She found that some students endured negative experiences; being ridiculed and the target of psychological blows from other nurses that could be suggestive of bullying practices. Such elements can however, affect the personal and professional identities of students in a way that leads students to change or alter their beliefs or images of nursing (Randle, 2001). Occasionally, students may feel they need to subjugate these beliefs in an attempt to comply or be accepted.

Yonge, Myrick, and Haase (2002) acknowledged undergraduate nursing students seem to experience a considerable amount of stress during their education, compared with their first year as graduate nurses. Negative clinical experiences can lead to feelings of frustration and discouragement. Ultimately, students can become stressed, disillusioned, and unable to assimilate into the nursing team and learn practical skills effectively (Yonge et al., 2002). When preceptorship is successful students are able to experience the true realities of the profession and learn skills and knowledge while in a safe and encouraging environment (Yonge et al., 2002).

\section{A welcoming environment}

Chesser-Smyth (2005) explored students' experiences in Ireland on their first clinical placement. The purpose of the study was to develop strategies to improve future clinical placements. The critical elements of the study were the importance of how the students were initially received on their clinical and the impact that mutual respect and positive regard had on the confidence of students (Chesser-Smyth, 2005). The elements identified by Chesser-Smyth (2005) played a vital role in the 'make or break' nature of the clinical placement. Chesser-Smyth (2005) found that students who were made to feel welcomed, who experienced reciprocal respect and positive regard, expressed higher levels of self-awareness and self-esteem. These themes, incorporated with a positive learning environment, enhanced the learning process through collaborative support and encouragement. Support and encouragement ultimately enabled higher levels of confidence, a reduction in anxiety and ultimately a positive clinical experience (Chesser-Smyth, 2005). 


\section{A strategic approach}

According to Donaldson and Carter (2005) a positive learning environment can be achieved with the implementation of role modelling strategies. Students would first observe the skill or behaviour and be given opportunities to practice, during which encouragement and constructive feedback is implemented to facilitate modification and improvement prior to completing formal assessments (Donaldson \& Carter, 2005). Berry (2005) supports this research adding that a positive clinical experience can be assured if students are partnered with registered nurses who have expertise in both clinical skills and an ability and willingness to teach.

Reid-Searl and Dwyer (2005) outlined strategies within a clinical learning cycle and implemented these into their undergraduate nursing program to assist educators in supervising students on clinical. The clinical learning cycle is a sequence of events employed prior, during and after clinical and places the focus on clinical educators in having the role of and responsibility for facilitating a clinical environment. Chesser-Smyth (2005) supported this model also and found clinical placement coordinators were influential in bridging the gap between theory and practice.

\section{Looking for a positive prognosis}

Beadnell (2006) investigated possible reasons for the shortfalls in numbers of graduating nurses and its impact on the Australian health care system. She indicated that students who secured a place in an undergraduate degree had to then deal with clinical placements that may not result in a positive experience. Such experiences can have far reaching consequences on students' choices and ability to become fully qualified practicing nurses as has been discussed in previous research. To produce a positive learning environment interpersonal relationships are essential, according to Dunn and Hansford (1997), 'with student satisfaction both a result of and significant in creating a positive learning environment' (as cited in Midgley, 2006:339).
Overall students need to feel welcomed, respected, and accepted as part of the nursing culture to ensure their clinical placements have a positive beginning. A positive clinical experience is imperative to ensure students complete undergraduate education and become registered nurses if the health care system is to take a step forward in an effort to address our current shortage of nursing workforce in the long term.

\section{Method \\ Underpinning philosophy}

Phenomenology, specifically Heideggerian philosophy was the chosen methodology for this research. Phenomenology focuses on understanding particular phenomenon through capturing the lived experiences of people who experience that phenomenon. Phenomenology is primarily concerned with the nature of human experience and what this means to us (Walton \& Madjar, 1999). The interpretation and understanding of life processes allows a deeper understanding of human behaviour that at most times is complex (Schneider, Elliott, LoBiondo-Wood, \& Haber, 2003). Roberts and Taylor (2002) simplify this approach as discovery, exploration and description of a phenomenon and 'the study of things within human existence' (p. 319). When studying phenomena the researcher needs to not only look at these phenomena themselves, but also the experience the participants have through their interaction or relationship with these phenomena.

\section{Heideggerian philosophy}

One of the most powerful examples of phenomenological description is the analysis of beingin-the-world developed by Heidegger (Dreyfus, 1991). The term being-in-the-world represents the concept that as entities in the world, we do not exist separately from what we experience in that world, they are two parts of the one whole (Dreyfus, 1991; Heidegger, 1962). Being-inthe-world is how we interact with and relate to our surroundings, how we as entities as humans 
in the world exist, our being. Dasein is the term used to describe each one of us as being; translated Dasein means being-there (Dreyfus, 1991).

\section{Lived experience}

Lived experience is a key component to phenomenological enquiry as it is the study of lived experience (Holloway \& Wheeler, 2002). Phenomenology does not set out to change the world. Phenomenology sets out to present lived experience and to discover meaning. Phenomenology hopes to discover a shared meaning, to give the readers, participants, and researchers that ' $a$ - $h a$ ' moment where we can relate to the meanings and themes within that research (Taylor, 1994).

Through everyday existence and tending to daily activities, we gain knowledge about things of interest and from this everyday existence, we gain what has been termed lived experience (Taylor, Kermode, \& Roberts, 2007). Lived experience relates to a unique, individual meaning of everyday existence that one may not be consciously aware. Through the process of recalling how one lived or experienced a particular event, experiences can be brought to a conscious level (Kleiman, 2004). Once these experiences are in conscious thought we can begin to make sense of the experience and thus find meaning, which is unique to individuals, or meaning that may resonate with others (Taylor et al., 2007).

\section{Hermeneutic interpretive phenomenology}

Interview transcripts of the participants' experiences of their first acute clinical placement formed a textual expression of the students' recall of their clinical placement as they remembered it. The process of reflective writing attempts to place the researcher in the time and space of the students' experiences. A textual activity such as reflective writing enables human existence to be studied using a hermeneutic phenomenological approach, which according to van Manen (1990:38) is:

phenomenological because it is the descriptive study of lived experience (phenomena) in the attempt to enrich lived experience by mining its meaning: hermeneutics because it is the interpretive study of the expressions and objectifications (texts) of lived experience in the attempt to determine the meaning embodied in them.

Hermeneutic interpretive phenomenology was the most appropriate philosophical approach when researching the 'meanings of a phenomenon with the purpose of understanding the human experience' (Crist \& Tanner, 2003:202). Interpretive methodology is the science of interpreting human meaning and experience (Gadamer, 1976, cited in Crist \& Tanner, 2003). When applying a hermeneutic phenomenological approach to analysing the participants' stories, the aim was to describe their experience. More so, to interpret what these experiences were in an attempt to understand what the lived experiences meant to the participants.

\section{Methods GUIDING the STUdY Recruitment of participants}

The six participants were undergraduate nursing students in first semester of second year of the Bachelor in Nursing Degree at a major rural university in Victoria, Australia. Each student was enrolled in the acute medical and surgical nursing unit, which incorporated a compulsory clinical placement. The students undertook their placement in an acute clinical facility for the duration of a 3-week period. Students were allocated to areas within the clinical facility such as general surgical, general medical, respiratory and colorectal where patients were experiencing acute episodes of conditions specific to these areas. Students repeating the acute nursing unit were excluded from the study as these students had previously 'experienced' their first 
acute clinical placement. Prior to this clinical placement, participants had only completed a 2 -week placement in an aged care facility during the first-year of the undergraduate course. Participants had not previously undertaken any undergraduate clinical placements in an acute hospital setting.

Participants were recruited through advertisements on student notice boards and during teaching sessions. Expressions of interest were sought from students about to undertake their first clinical experience in acute care. An explanatory statement outlining the study was forwarded to all respondents along with a consent form to sign if they agreed to participate. Seventeen students responded to the initial invitation. From those 17 students, 11 consented to participate by signing and returning the consent form. The final number of participants (six) was determined by the timing of their first acute clinical placement which occurred in the eighth week of semester one.

The six participants were all female and with the exception of one, all were enrolled as full-time students. Five were mature aged students with one a direct-entry school leaver. Four of the participants had completed a bridging course through a TAFE provider. Regarding exposure to the health care industry, three participants were personal care attendants with two having no experience in the health care industry and one being a Division 2 registered nurse. In Victoria there are two levels of nurse; the Registered Nurse Division 1, and the Registered Nurse Division 2. A Division 2 registered nurse is also known as an Enrolled Nurse in other States and Territories (Nurse Policy Branch, 2009).

All participants worked closely with a number of preceptors for the duration of their 3-week clinical placement. Preceptors were Division 1 registered nurses with their nursing experience ranging from graduate nurses through to the most experienced. Appropriate preceptors were determined by roster allocations and availability throughout the placement.

\section{Ethical considerations}

Ethical approval was granted by the University ethics committee. Anonymity was maintained throughout the research process with the use of pseudonyms. The presence of an unequal relationship between the participants and chief investigator requires acknowledgement. During the data collection the chief investigator was the participants' lecturer. Participants were advised that involvement was purely voluntary. Withdrawal could occur at anytime up to data analysis, with their decision to withdraw or continue having no bearing on academic achievement or future results.

\section{Data collection methods}

In line with a phenomenological approach, the language of the participants was the tool utilised in the data collection process. Data were collected 2-3 weeks after completion of clinical placement at a mutually agreed time and place by use of audio-taped interviews, with duration of no longer than $1 \mathrm{~h}$. Participants were asked to recount their experience. An initial open-ended question was asked: 'tell me what it was like for you when you first went on clinical in the acute care area?' Subsequent questions were asked to clarify initial responses and varied from participant to participant. Each interview was taped and transcribed verbatim to form a documented narration of each participant's response.

\section{Thematic analysis}

Max van Manen's (1990) analysis technique of 'selecting and highlighting' was applied to all transcripts. This approach required reading and re-reading transcripts to identify statements and phrases that revealed what the students' experiences were like. These statements, or emerging themes, were highlighted and coded using either a key word or words from that statement. As themes reoccurred, or became common amongst students' recall of their experiences, essential or main themes were developed in order to grasp the true meaning of the experiences of the participants. On completion of the thematic analysis, 
all identified themes were integrated into one of three overarching themes. In analysing the participants' experiences, the aim was to determine the 'experiential structures' that made their experience what it was. Max van Manen (1990) describes phenomenological themes as structures of the experience being analysed, they are not simply categorical statements or conceptual formulations of that experience.

During thematic analysis four existential themes were utilised in reflecting on the lived experience of the participants' clinical experience or how they experienced their lifeworld during clinical placement; lived space, lived body, lived time and lived other.

Another aspect of van Manen's work that was at the forefront of analysis was his description of the significance of uncovering thematic aspects. Max van Manen eloquently depicted themes as being 'the stars that make up the universes of meaning we live through. By the light of these themes we can navigate and explore such universes' (1990:90). In identifying themes, the experiences of the participants were explored and described, meaning was attached and ultimately, a deeper understanding was developed.

\section{FINDINGS}

Through hermeneutics a number of themes were identified, offering one interpretation of the experiences of the second year undergraduate nursing students undertaking their first acute clinical placement. The themes that emerged included, being overwhelmed and confronted, patients as people, and perceptions of preceptors. Within these three main themes a number of sub-themes were also articulated and positioned. Narratives from the participants are used to place a context on the themes identified.

\section{Being overwhelmed and confronted}

In describing their experiences on clinical, terms such as 'overwhelming', 'confronting', 'disorientating' and 'scary' were a common thread woven through all of the participants' stories. An unfamiliar and busy environment with its associated sights, noises and smells caused Kate to feel overwhelmed and disorientated. The participants were also significantly overwhelmed by, and confronted with, the patients and their associated illnesses.

With the exception of Marie, there was one powerful experience that all participants described; the feeling of being overwhelmed or confronted by the patients they each cared for. The patients themselves appeared not to be the sole trigger for these feelings. Rather the illness, pain and suffering the participants witnessed their patients experiencing were the prompts. As Marie had an extensive amount of experience in the health care industry as a Division 2 registered nurse, she had previously been exposed to patients and their illness experience prior to her first acute clinical placement, and thus was not overwhelmed by this issue; whereas Sabrina, Faith, Emma, Mary and Kate had minimal exposure to, or experience with, patients in the acute stages of illness.

The participants were overwhelmed by seeing patients experience illness processes and associated physical and emotional manifestations caused by their respective illnesses. Sabrina recalled her feelings regarding initial contact with her patients as confronting:

I think initially it was very confronting seeing such acutely sick people and they were very sick, huge abdominal surgery. So that knocked me on my feet, my reaction to seeing sick people.

\section{Patients as people}

During thematic analysis the theme patients as people began to emerge as the participants began to speak about their 'patients'. The participants referred to the patients according to their diagnosis, as 'patients'. As the placement progressed, the participants were able to spend more time caring for and getting to know the patients for 'who' they were, not just a diagnosis; as people. 


\section{Perceptions of patients}

In the early stages of clinical placement participants viewed their patients as 'the lady with Hep C', or 'the man with inoperable cancer'. Compounding the feelings of being overwhelmed by how acutely unwell these patients were, the participants then became increasingly overwhelmed when they realised these 'patients' were real people; people at their most vulnerable. They were people who were married, had children, were carers and had careers.

The participants were able to look beyond the circumstances that lead the patients to become hospitalised, to be non-judgemental and view them as people requiring nursing care during a time of significant vulnerability. During this time of vulnerability, the participants were able to see how the patients coped and managed their illness in ways that surprised them. Faith found she was enthralled by the struggles some patients experienced during their illness. Mary and Kate were amazed by the optimism some of their patients displayed when faced with the possibility of a terminal diagnosis. Even in their most vulnerable state, patients were able to express gratitude towards the students.

The participants unexpectedly found that although the patients were in such vulnerable states with terrible and distressing circumstances surrounding their illnesses, they displayed gratitude towards the students. This expression of thanks was difficult to comprehend for Sabrina, Faith, Emma and Kate who all experienced gratitude from their patients. Sabrina was told her presence during her patient's time of immense physical pain was comforting; a time where Sabrina was not sure the patient was even aware of her presence. Faith was surprised by a Chinese patient expressing a myriad of 'thank-you's' when Faith was unaware that she could even speak any English. All of the participants were shown by the patients that they had made a difference to them and their hospitalisation. Such an acknowledgement answered a common question the participants wanted answered, 'What difference could I make, I'm only a student'.

\section{Making a difference}

One of the cornerstones of a student's clinical placement is the provision of comfort to the patients. When a participant was able to positively contribute to the recovery or palliation of a patient, they felt they had been able to 'do real nursing'. By providing comfort to patients, participants felt worthy, valued and that they have made a difference to that patient. At times however, there were participants who felt their role in the provision of care was limited because they were only students. Sabrina, Emma and Kate thought that as they were 'just a student', and expressed 'what could they do to make a difference to the care of a patient?'

Some of the participants did not think they could, or would, have any significant influence on their patients' stay in hospital. However, as they discovered some not only had an impact on the patients but also their patients' families. Kate developed a close professional relationship with a Samoan man who had inoperable gastric cancer and whose prognosis was poor. On her last day on clinical placement, the family gave her a small gift in appreciation of the care she provided. Such a gesture had Kate questioning why, in such an emotional and devastating time in their lives, they would take the time to thank her.

\section{Perceptions of preceptors}

The theme 'perceptions of preceptors' encompassed how participants viewed their preceptors throughout the clinical placement. Perceptions of their preceptors influenced the experiences had during placement and over time led to a familiarity, increased confidence and the ability to independently show signs of initiative. Ultimately, participants were acknowledged for their clinical initiatives by their preceptors. The sub-themes of 'familiarity breeds confidence' and 'impact of 
acknowledgment' will expand on these findings further.

The participants in this research had both comparable and varying experiences with their preceptors during clinical placement. Not only did the patients have a significant impact on the clinical experience, but also preceptors and general nursing staff had just as a significant impact. The participants recalled feeling they were a burden, not valued or included as part of the nursing team. At times, they were intimidated by the preceptors as some participants were made to feel uncomfortable when receiving feedback by some preceptors, especially when the actions of the students were not in line with the preceptors expectations. Mary remarked:

I'd do something and she'd say oh well, you didn't do that right so now I'm going to have to do it again; she sort of made you feel really intimidated and sort of small.

Emma was able to articulate the impact a positive experience with a preceptor can have:

Now I'm excited again...whenever I think about my placement I think about my preceptors and I find myself thinking about them in a lot of the things that I do when I'm learning as well...they stay with you.

With the exception of Emma, all of the participants experienced some degree of negativity towards them at some stage during their clinical. The negativity manifested as attitudes expressed, sometimes quite loudly by the general nursing staff and the preceptors allocated to the students. Sabrina and Marie admitting their expectations surrounding their 'ideal' preceptor were sadly unmet. Sabrina recalled:

I didn't find them to be supportive or guiding or patient or really interested in as to why I was there. I think, yeah, my expectations were way out, really way out.... lot of those nurses, they seem to forget that they were students once and not that long ago either.

With Marie stating:
If I'd have been someone who had never worked in a hospital before or had no nursing knowledge at all, I probably would have walked off and never gone back to nursing.

Marie's story adds an interesting perspective regarding perceptions of preceptors and expectations. As Marie was the only Division 2 nurse amongst the participants, her experience centered mainly on her interactions with her preceptors. Her expectations were different to the other participants as she was not entirely sure how she would cope with a change in role from a fully qualified health professional, to that of a novice. Marie spoke of her concerns with firstly being 'found out' to be a Division 2 nurse; would they expect more from her compared to the other students who were not Division 2 nurses? Secondly, she was fearful of the personal expectations placed on her and also those she imagined may have been placed on her by the preceptors. Her concerns and fears were soon allayed:

As they said, doesn't matter, you might be a Div 2 and you can do the basics but you are here to learn as a Div 1, we are not worried about you being Div 2 .

\section{Familiarity breeds confidence}

Students undertaking their first clinical placement are met with many new, exciting and sometimes confronting experiences. Some feel disorientated by unfamiliar environments, people and routines. A student who is lacking in confidence may tend to stand back, not ask questions, be fearful of conducting procedures and may be viewed to be disinterested. A student viewed to be disinterested may actually be lacking confidence or be fearful of causing harm to their patients; they may be frightened of 'being a nurse'. Participants who were confident actively sought out learning prospects, asked questions and used their initiative to work within their scope of practice when any opportunity presented itself. There were other participants who lacked the confidence to ask 
questions and may have been viewed as not having the same initiative. This research showed that each participant was an individual in their level of self-confidence, and the degree this confidence influences their clinical placement experience was palpable.

Kate described how her lack of confidence affected her ability to initiate nursing care:

You can only do what you can, like, what is in your nursing role; and for me as a student, that was even less so I didn't feel confident a lot of the time to just go in and do things. I was like, always the shadow of my nurse.

The participants began to experience higher levels of confidence when they became more familiar with the clinical environment, the patients they cared for and the preceptors who worked alongside them. They were able to selfinitiate planning and implementing nursing care independent of their preceptor, though within their role as a student. With this familiarity and becoming accustomed to the clinical environment, the participants developed significant increases in confidence which in some cases was recognised by their preceptors. The result was acknowledgement that they were a valued team member and could be trusted to take on more responsibilities in patient care.

\section{Impact of acknowledgment}

Acknowledgement is an important issue not only for undergraduate nursing students but for all nurses. Being acknowledged for positive actions can provide a sense of accomplishment, increased confidence and a feeling of self-worth and value. Acknowledgement can also mean the student has been accepted as part of the team. Having their contributions recognised can give students the confidence they require to assist them in continuing with their placement and also their course. Mary described how she felt when acknowledged by her preceptors:

When you did do things to help them out they'd always say thank you for doing that, or it's good to see some initiative, and stuff like that; so it was good getting a bit of praise too. It just makes you feel like you're doing a good job and that you can do it.

\section{Discussing THE MEANING OF THEIR EXPERIENCES}

There is a paucity of literature around students feeling overwhelmed when confronted with caring for patients in hospital. However in her work entitled 'The emotional labour of nursing', Smith (1992) states that nursing students are frequently exposed to situations that evoke emotional reactions, especially situations involving patients. She suggested that the emotionally charged situations students found themselves in 'went beyond the medical and technical definitions of their training and back to nursing as people work' (p. 59). Smith also reported students personally invested in care they provided their patients, which enabled them to make a difference to that patient. A compelling statement by a participant of Smith's study parallels why some of the participants in our study were confronted and overwhelmed; 'if people don't matter then you can't do nursing' (p. 132). Patients, rather people, did matter to the participants. This lead to feeling overwhelmed and confronted because they were concerned for their well-being.

Heidegger proposed we are always being towards something and for the most part it is death. However, these participants were being towards being better students and wanting to make a difference to the patients they cared for. Conversely, the angst or feelings of overwhelming anxiety confronting them prevented being better students. In situations where anxieties or fears overwhelm us, Dasein is forced to look at itself, to look inward, to face these anxieties or fears. We are unable to hide in the everydayness of existence at that moment (Dreyfus, 1991). We are forced to face our anxieties and fears that overwhelmed us and ask ourselves about the circumstances causing such disposition.

The participants questioned themselves as to why feelings of being overwhelmed were 
experienced. Being confronted meant they became consciously aware of their being-in-theworld, the world of the patient, their world as a student nurse. The participants were overwhelmed and confronted because they were concerned for the patients. Heidegger professed Dasein's beingin-the-world was never in isolation, but was connected with others by way of intimate relationships (Dreyfus, 1991). Dasein's way of relating to things in the world was to have concern for another (besorge), and as humans we have concern for those we have relationships with; we express a solicitude, or fursorge, towards others we have concern for their wellbeing (Dreyfus, 1991). The overwhelming feelings that confronted the participants also made them realise that these patients were not 'just patients' but were 'people'.

The participants began to see their patients as people during their clinical placement, which at times was overwhelming and confronting. When anxieties manifest or confront us we are acknowledging that something matters and that we care. To care is to express how Dasein is able to be-in-the-world. According to Heidegger 'it is because our basic way of being-in-the-world is care (Sorge) that we can have concern (Besorge) for entities in the world and solicitude (Fursorge) for others' (Dreyfus, 1991:24). Students are concerned for their patients, therefore they care about them. As nurses we are able to assist in reducing the vulnerability of patients we care for. Nursing students are in the same position. The participants were able to reduce the degree of vulnerability their patients experienced by being for the patients. Stein-Parbury (2005) attests that in demonstrating we care for patients we are being for our patients. In being for their patients, the students were able to make a connection, a human connection. Making such a human connection has been identified by Stein-Parbury as being a central component of nursing. However, making a human connection was not immediate for the students.

There is a paucity of research on the impact patients have on students. Nurses care for many patients throughout their careers, ranging in age across the entire lifespan. As nurses we have the ability to 'connect' with many of our patients, but not all will have a significant influence over our ongoing careers as nurses. There are of course those who do. The nature of this research invited participants to identify with patients they had nursed. These memories may have profound influences on the careers of the participants, both as students and as registered nurses in the future.

Participants initially viewed the patient as a 'patient with a diagnosis'. As the therapeutic relationship progressed, the participants began to see the patients as people. As the student nurse-patient interactions became more meaningful a connection was made, and with this connection, participants expressed compassion for the patients. Participants began to see patients as not just 'sources of data ... or ... passive recipients of care' (Stein-Parbury, 2005:3). They were people the students engaged with, showed compassion for and developed therapeutic relationships. It is through a therapeutic relationship that concern, care and commitment can be expressed (Stein-Parbury, 2005). The outcome for the patients was that these students did make a difference.

An outcome for the participants was that preceptors also made a difference. The findings relating to perceptions of preceptors are congruent with the literature identified in the literature review. Cahill (1996) indicated that students place a significant emphasis on the attitudes of trained nurses towards them as students. Further to this finding is the influence that attitudes of registered nurses have on whether clinical placements are viewed by the students as satisfying or not. Randle (2001) found that registered nurses appeared to have the most influential impact on self-esteem of undergraduate nursing students. She found that students endured negative experiences, with students being ridiculed and the target of psychological blows from other nurses that could be suggestive of bullying practices. 
Chesser-Smyth (2005) discovered the importance placed on how students were initially received on their clinical and the impact that mutual respect and positive regard had on the confidence of students.

Nursing students do not want to be viewed as being a burden to other nursing staff including their preceptors. Students want to be viewed as being a valuable, actively participating health care team member. They want to be helpful and useful to their preceptors. When students are made to feel they are a burden, or they perceive they are a burden, the effects can not only be detrimental to their placement but also to their course continuation. Bearing this notion of being a burden in mind, most participants actively sought out opportunities to participate and learn in the aim of becoming a worthwhile member of the team. In exchange participants hoped to be taught, supported by and welcomed into the health care team as a valued and respected member.

van Manen's existential theme previously identified in this paper pertinent to 'perceptions of preceptors' is lived other (relationality). Lived other refers to how we relate to others we encounter within shared interpersonal space (van Manen, 1990). van Manen's explanation can be applied to the relationship between students and preceptors: it is one of 'lived relation to the other' (p. 106). Preceptors who display confidence and trust towards students portray a supportive relationality to the student. Upon receiving support and trust from their preceptors, participants began to establish a sense of value and independence as a result of the confidence and trust shown by the preceptors '...confidence and trust, without which it is difficult to make something of oneself' (van Manen, 1990:106).

As participants progressed through clinical placement their confidence evolved, even more so when they became familiar with the patients, preceptors and clinical environment with each encounter. According to Heidegger (1962), the way we encounter non-human entities is termed ready-to-hand and refers to equipment or tools manipulated in order to 'do something'. For students, 'familiarity' is the necessary tool ready-to-hand in order for the students to 'do nursing'. Familiarity as a tool enables students to become accustomed with their world at a particular time and space. Hence, when familiarity is ready-to-hand, confidence increases and students are able to undertake the task at hand, to do nursing. However, as suggested by Mulhall (1993), we do not focus on the tool itself in our everyday encounters, but on 'the work for which they are ready-to-hand' ( $p$. 112): only when the tool is lost or obstructed do we become explicitly aware of its totality. When familiarity is removed, students' confidence is hindered and their ability to 'do nursing' is diminished.

When participants experienced the unfamiliar and confidence was hindered, being acknowledged had a significant impact on their ability to 'do nursing'. Acknowledgement may come in many forms. During clinical placement participants recalled being acknowledged by a fellow student for showing support to them, a nursing staff member recognised a participant's efforts to care for a patient or directly from a patient a participant was caring for at the time. When or by whom such acknowledgement or recognition comes made little difference to the participant, as long as acknowledgement was given. One profound impact of acknowledgement all of the participants experienced was they were able to admit to themselves that nursing has been the right career choice, and their first acute clinical placement was the motivation they needed to continue on with their studies.

The impact of receiving acknowledgement for 'doing nursing' confirmed for the participants they are being true to who they are as themselves, as student nurses, as potential Division 1 nurses, and as learners. They were trying to be accepted as able to cope with whatever the clinical milieu presents to them as authentic beings. Gelven (1989) comments on Heidegger's notion 
of authenticity by stating to be our authentic self our conscious must be heard; a self awareness must arise. Participants who were consciously aware of their 'authentic self' were able to acknowledge who they wanted to be as nurses. Being able to acknowledge to themselves the right decision had been made can be paralleled with Heidegger's notion of resoluteness. Resoluteness was chosen as a description of existing as authentic beings (Gelven, 1989). To be resolute means to have resolved or made a decision. Gelvin states as authentic beings we have the freedom to choose our own existence. As authentic beings, students are resolute in choosing to 'do nursing'.

\section{Limitations of the research}

The research was confined to one campus of one school of nursing and midwifery in one university in Victoria. The sample size, though appropriate for a phenomenological approach, may be regarded as small. Participants were only drawn from one clinical context, that being medical/ surgical and from 1 year level. Results may not be representative of second year nursing students in general, but may resonate with other second year students. A final limitation is the presence of an unequal relationship between researcher and participant. There is the possibility students' responses may have been influenced by this relationship.

\section{Recommendations}

From this research a number of recommendations are put forward. Undergraduate nursing courses should include in-depth education on the illness experience from a patient's perspective as a means to provide insight into how patients cope, or do not cope, with their illness. Such strategies may prepare students to nurse acutely unwell patients more effectively. Undergraduate nursing units delivered in the second year of the course should allocate scheduled clinical preparation sessions during lecture or laboratory time. A final recommendation is the application of current research on clinical placements from the preceptor's perspective. This research will not only inform students of what preceptors may be expecting and looking for in students' behaviour on clinical placement but also so they may be made aware of the important role preceptors play in the process of undergraduate nursing education. These recommendations may better prepare students for their first acute clinical placement with the aim of achieving a positive clinical experience.

\section{Avenues of future research}

Conducting this research highlighted possible avenues of further research. Nursing researchers could investigate the experience of role transition for Division 2 Registered Nurses commencing an undergraduate nursing degree. Another area worthy of exploration is students enrolled in undergraduate nursing courses gaining regular employment in the health care industry, and whether there is any impact or influence on clinical placement experience.

\section{Conclusion}

This paper has explored and described the experiences of second year undergraduate nursing students at one university in Victoria, Australia undertaking their first acute clinical placement. The participants provided the opportunity to see into the world of a student nurse and what it was like to undertake their first acute clinical experience. In particular it offered insight into how these experiences influenced their journey as a student, and possibly, their future career in nursing. Findings inform why some students consider discontinuance of their studies and how the experience impacts on decisions about future nursing practice. This research is useful to tertiary institutions in preparing students, placement areas and staff who preceptor students with the aim of facilitating positive experiences and assisting students' motivation in future clinical placements. 


\section{References}

Beadnell, C. (2006). Nurse Education: Our health depends on it. Australian Nursing Journal, 13(7), 25-27.

Berry, J. (2005). A student and RN partnered clinical experience. Nurse Educator, 30(6), 240-241.

Cahill, H. (1996). A qualitative analysis of student nurses' experiences of mentorship. Journal of Advanced Nursing, 24(4), 791-799.

Chesser-Smyth, P. (2005). The lived experiences of general student nurses on their first clinical placement: A phenomenological study. Nurse Education in Practice, 5, 320-327.

Cope, P., Cuthbertson, P., \& Stoddart, B. (2000). Situated learning in the practice placement. Journal of Advanced Nursing, 31(4), 850-856.

Crist, J., \& Tanner, C. (2003). Interpretation/ analysis methods in hermeneutic interpretive phenomenology. Nursing Research, 52(3), 202-205.

Donaldson, J. H., \& Carter, D. (2005). The value of role modeling: Perceptions of undergraduate and diploma nursing (adult) students. Nurse Education in Practice, 5, 353-359.

Dreyfus, H. (1991). Being-in-the-world: A commentary on Heidegger's being and time Division 1. Cambridge, MA: The MIT Press.

Gelven, M. (1989). A commentary on Heidegger's being and time (Rev. ed). DeKalb, IL: Northern Illinois University Press.

Heidegger, M. (1962). Being and time, John Macquarrie \& Edward Robinson (trans). London: Blackwell Publishing Ltd.

Holloway, I., \& Wheeler, S. (2002). Qualitative research in nursing (2nd ed). Oxford: Blackwell Science.

Kleiman, S. (2004). Phenomenology: To wonder and search for meaning. Nurse Researcher, 11(4), 7-19.

Midgley, K. (2006). Pre-registration student nurses perception of the hospital-learning environment during clinical placements. Nurse Education Today, 26, 338-345.

Mulhall, S. (1993). On being in the world: Wittgenstein and Heidegger on seeing aspects. London: Routledge.
Nurse Policy Branch. (2009). Nursing in Victoria. Becoming a nurse. Retrieved July 3rd, 2009 from http://www.health.vic.gov.au/nursing/career/ becoming.

Randle, J. (2001). The effect of a 3-year preregistration training course on students' self-esteem. Journal of Clinical Nursing, 10(2), 293-300.

Reid-Searl, K., \& Dwyer, T. (2005). Clinical placements for undergraduate nursing students: And educators guide. Australian Nursing Journal, 12(9), 21-24.

Roberts, K., \& Taylor, B. (2002). Nursing research processes: An Australian perspective (2nd ed.). Melbourne: Nelson.

Schneider, Z., Elliott, D., LoBiondo-Wood, G., \& Haber, J. (2003). Nursing research; methods, critical appraisal and utilization (2nd ed.). New York: Mosby.

Smith, P. (1992). The emotional labour of nursing: How nurses care. London: Macmillan Education.

Spouse, J. (2000). An impossible dream? Images of nursing held by pre-registration students and their effect on sustaining motivation to become nurses. Journal of Advanced Nursing, 32(3), 730-739.

Stein-Parbury, J. (2005). Patient and person (3rd ed.). Sydney: Elsevier.

Taylor, B. (1994). Being human: Ordinariness in nursing. South Melbourne: Churchill Livingston.

Taylor, B., Kermode, S., \& Roberts, K. (2007). Research in nursing and health care: Evidence for practice (3rd ed.). South Melbourne: Thomson.

van Manen, M. (1990). Researching lived experience: Human science for an action sensitive pedagogy. New York: State University of New York Press.

Walton, J. A., \& Madjar, I. (1999). Nursing and the experience of illness: Phenomenology in practice. St. Leonards: Allen and Unwin.

Yonge, O., Myrick, F., \& Haase, M. (2002). Student nurse stress in the preceptorship experience. Nurse Educator, 27(2), 84-88.

Received 15 April 2009 Accepted 01 September 2009 
Copyright of Contemporary Nurse: A Journal for the Australian Nursing Profession is the property of eContent Management Pty. Ltd. and its content may not be copied or emailed to multiple sites or posted to a listserv without the copyright holder's express written permission. However, users may print, download, or email articles for individual use. 